Таблица 2 индексу ОХ/ЛПВП. Как видно из табл. 2, в ис-

Характеристика показателей липидного обмена у обследованных к концу третьей недели заболевания $\left(\mathrm{M} \pm \mathrm{S} ; \mathrm{M}_{\min }-\mathrm{M}_{\max } ; p-\right.$ критерий достоверности)

\begin{tabular}{|l|c|c|c|}
\hline \multicolumn{1}{|c|}{ Показатель } & $\begin{array}{c}\text { Исследуемая } \\
\text { группа }\end{array}$ & $\begin{array}{c}\text { Контрольная } \\
\text { группа }\end{array}$ & $p$ \\
\hline ОХ, ммоль/л & $5,4 \pm 1,3$ & $5,8 \pm 1,4$ & 0,2 \\
& $3,20-8,20$ & $2,79-10,0$ & \\
\hline ТГ, ммоль/л & $2,4 \pm 1,6$ & $2,4 \pm 1,7$ & 0,9 \\
& $0,80-5,51$ & $0,79-8,40$ & \\
\hline ЛПНП, ммоль/л & $5,2 \pm 3,8$ & $6,6 \pm 3,7$ & 0,2 \\
& $1,49-11,30$ & $1,10-13,40$ & \\
\hline ЛПОНП, ммоль/л & $2,7 \pm 1,0$ & $2,9 \pm 1,3$ & 0,8 \\
& $0,95-4,0$ & $0,95-5,42$ & \\
\hline ЛПВП, ммоль/л & $1,0 \pm 0,3$ & $0,9 \pm 0,2$ & 0,1 \\
& $0,52-1,90$ & $0,50-1,83$ & \\
\hline КА & $4,6 \pm 2,1$ & $5,8 \pm 2,3$ & 0,01 \\
& $2,06-11,31$ & $1,18-12,40$ & \\
\hline ОХ/ЛПВП & $5,6 \pm 2,1$ & $6,8 \pm 2,3$ & 0,01 \\
& $3,06-12,31$ & $2,18-13,40$ & \\
\hline ЛПНП/ЛПВП & $5,5 \pm 4,0$ & $8,0 \pm 5,7$ & 0,1 \\
& $1,53-13,50$ & $0,84-22,8$ & \\
\hline
\end{tabular}

следуемой группе значения данных показателей оказались ниже, чем у пациентов контрольной группы. Также отмечено, что в контрольной группе значения ОХ, ЛПНП и ЛПОНП несколько выше, чем в группе пациентов с ЛГ, развившейся в подостром периоде ИМ.

Полученные результаты не полностью соответствуют известным литературным данным, что обусловлено различиями в дизайнах исследований. Следует учесть, что низкий уровень атерогенных фракций OX у пациентов с ЛГ, развившейся в подостром периоде ИМ, может служить маркером неблагоприятного прогноза.

Заключение. В ходе исследования установлено, что мужчины молодого и среднего возраста с ЛГ, развившейся на фоне ИМ, характеризуются более низкими уровнями КА и индекса ОХ/ ЛПВП, определяемых в конце третьей недели заболевания, чем пациенты с нормальным уровнем СДЛА в обе точки измерения или нормализацией этого параметра в подостром периоде ИМ. Полученные данные необходимо использовать для разработки прогностической модели развития ЛГ в подостром периоде ИМ.

DOI $10.52727 / 2078-256 X-2021-17-3-76-78$

\title{
РОЛЬ МЕТАЛЛОПРОТЕИНАЗ И ТКАНЕВЫХ ИНГИБИТОРОВ МЕТАЛЛОПРОТЕИНАЗ В РАЗВИТИИ КОРОНАРНОГО АТЕРОСКЛЕРОЗА
}

\author{
Я.В. Полонская, Е.В. Каштанова, Е.М. Стахнева, Е.В. Садовский, Ю.И. Рагино \\ Научно-исследовательский институт терапии и профилактической медицины - \\ филиал ФГБНУ «Федеральный исследовательский иентр Институт цитологии и генетики ССО РАН», \\ Новосибирск, Россия
}

Сердечно-сосудистые заболевания считаются основными причинами заболеваемости и смертности во всем мире. Повышенная жесткость и снижение эластичности сосудистой стенки из-за патологической кальцификации сосудов влияют на сердечно-сосудистые и цереброваскулярные заболевания с высоким уровнем смертности, приводит к ишемии миокарда, гипертрофии левого желудочка и сердечной недостаточности, вызывая тромбоз и разрыв бляшки. Начальные этапы кальцификации отчасти связаны с деградацией эластина с образованием минеральных отложений. Важную роль в этом процессе играют металлопротеиназы (ММП) и их ингибиторы. Дисбаланс ММП и тканевых ингибиторов металлопротеиназ (ТИМП) способствует атерогенезу, агрегации тромбоцитов и дестабилизации бляшек.

Цель. Изучить уровни ММП и ТИМП в стабильных и нестабильных бляшках коронар- ных артерий и оценить их влияние на кальцификацию и развитие нестабильности атеросклеротического очага.

Материал и методы. В исследование включено 78 мужчин с коронарным атеросклерозом, поступивших на операцию коронарного шунтирования. В ходе операции получен материал, содержащий атеросклеротические бляшки разных типов, который был разделен на фрагменты для гистологических и биохимических исследований. Концентрации ингибиторов тканевых металлопротеиназ ТИМП-1, ТИМП-2, ТИМП-3, ТИМП-4 в гомогенатах образцов анализировали методом мультиплексного анализа с использованием панели human panel PMM (MILLIPLEX card) на проточном флуориметре Luminex MAGPIX. Уровень остеопротегерина, остеопонтина, остеокальцина, остеонектина, ММП-9, ММП-3, ММП-7 и ММП-1 определяли иммуноферментным методом. Концентрацию изуча- 
емых показателей рассчитывали относительно белка. Статистическуюя обработку проводили в программе SPSS for Windows. Критерий статистической значимости составил $p<0,05$.

Результаты. В нестабильных бляшках были выше уровни остеокальцина в 1,86 раза, кальцитонина в 1,4 и кальция в 1,7 раза. Концентрации ТИМП-1 и ТИМП-2 также были выше по сравнению со стабильными (табл. 1). Уровни ТИМП-3 и ТИМП-4 в стабильных и нестабильных бляшках не различались.

Содержание ММП-1, ММП-7 и ММП-9 было почти в 2 раза выше в нестабильных бляш- ках, в то время как уровень ММП-3 был в 1,6 раза ниже, чем в стабильных (табл. 2).

В кальцинированных бляшках уровень ТИМП-1 и ТИМП-2 был ниже по сравнению с некальцинированными бляшками, содержание ТИМП-3 и ТИМП-4 не отличалось (табл. 3). Исследование ТИМП в атеросклеротических бляшках с различными размерами кальцификатов показало снижение уровня ТИМП-1 и ТИМП-2 с увеличением размера кальцификатов.

При изучении ММП-9 в образцах атеросклеротических бляшек мы выявили, что относительный риск формирования кальцификатов

Таблица 1

Уровень ТИМП в стабильных и нестабильных атеросклеротических бляшках

\begin{tabular}{|c|c|c|}
\hline Показатель & Стабильная бляшка \\
Q2 $(\mathrm{Q} 1 ; \mathrm{Q} 3)$ & $\begin{array}{c}\text { Нестабильная бляшка } \\
\text { Q2 }(\mathrm{Q} 1 ; \mathrm{Q} 3)\end{array}$ \\
\hline ТИМП-1, пг/мг белка & $1068,3(143,8 ; 4528,3)$ & $520,8^{*}(61,3 ; 6340,0)$ \\
\hline ТИМП-2, пг/мг белка & $927,1(335,7 ; 1566,1)$ & $622,4^{*}(223,1 ; 2162,3)$ \\
\hline ТИМП-3, пг/мг белка & $1424,8(778,4 ; 2014,3)$ & $1270,5(976,6 ; 1988,3)$ \\
\hline ТИМП-4, пг/мг белка & $209,7(107,9 ; 286,2)$ & $198,9(151,0 ; 305,1)$ \\
\hline
\end{tabular}

${ }^{*} p<0,05$ по сравнению со стабильными бляшками.

Таблица 2

Уровень ММП в стабильных и нестабильных атеросклеротических бляшках

\begin{tabular}{|c|c|c|}
\hline Показатель & $\begin{array}{c}\text { Стабильная бляшка } \\
\text { Q2 (Q1; Q3) }\end{array}$ & $\begin{array}{c}\text { Нестабильная бляшка } \\
\text { Q2 }(\mathrm{Q} 1 ; \text { Q3) }\end{array}$ \\
\hline ММП-9, нг/мг белка & $3,2(1,2 ; 5,4)$ & $6,3^{*}(2,9 ; 8,2)$ \\
\hline ММП-3, нг/мг белка & $3,8(1,7 ; 6,2)$ & $2,5^{*}(0,96 ; 4,4)$ \\
\hline ММП-7, нг/мг белка & $1,7(0,76 ; 2,4)$ & $2,32^{*}(1,25 ; 4,3)$ \\
\hline ММП-1, нг/мг белка & $107,6(62,3 ; 175,4)$ & $208,6^{*}(83,2 ; 256,7)$ \\
\hline
\end{tabular}

* $p<0,05$ по сравнению со стабильными бляшками.

Таблица 3

Уровень изучаемых маркеров в атеросклеротических бляшках с кальцинатами и без кальцинатов

\begin{tabular}{|c|c|c|}
\hline Показатель & $\begin{array}{c}\text { Атеросклеротическая бляшка } \\
\text { без кальцификатов } \\
\mathrm{Q} 2(\mathrm{Q} 1 ; \mathrm{Q} 3)\end{array}$ & $\begin{array}{c}\text { Атеросклеротическая бляшка } \\
\text { с кальцификатами } \\
\text { Q2 }(\mathrm{Q} 1 ; \mathrm{Q} 3)\end{array}$ \\
\hline ТИМП-1, пг/мг белка & $1170,43(98,2 ; 5465,7)$ & $339,38(43,66 ; 2485,75)^{*}$ \\
\hline ТИМП-2, пг/мг белка & $855,89(342,15 ; 2211,84)$ & $536,72(190,24 ; 1167,5)^{*}$ \\
\hline ТИМП-3, пг/мг белка & $1218,42(768,76 ; 1569,88)$ & $1327,14(842,54 ; 1902,36)$ \\
\hline ТИМП-4, пг/мг белка & $179,67(110,91 ; 269,05)$ & $211,33(123,35 ; 325,44)$ \\
\hline ММП-9, нг/мг белка & $2,24(1,22 ; 4,16)$ & $3,61(1,62 ; 5,08)^{*}$ \\
\hline ММП-3, нг/мг белка & $2,00(1,24 ; 4,38)$ & $2,05(1,52 ; 3,3)$ \\
\hline ММП-7, нг/мг белка & $0,62(0,29 ; 1,56)$ & $0,78(0,27 ; 2,41)$ \\
\hline ММП-1, нг/мг белка & $49,21(6,05 ; 299,3)$ & $71,37(21,09 ; 154,99)^{*}$ \\
\hline
\end{tabular}

\footnotetext{
* $p<0,05$ по сравнению с бляшками без кальцификатов.
} 
Корреляционные связи ТИМП с маркерами кальцификации (коэффициент Спирмена)

\begin{tabular}{|l|c|c|c|c|}
\hline \multicolumn{1}{|c|}{ Показатель } & ТИМП-1 & ТИМП-2 & ТИМП-3 & ТИМП-4 \\
\hline Остеокальцин & & $-0,296^{* *}$ & $0,284^{*}$ & $0,377^{* *}$ \\
\hline Остеонектин & & & $0,872^{* *}$ & $0,892^{* *}$ \\
\hline Остеопонтин & $0,552^{* *}$ & $0,684^{* *}$ & $0,529^{* *}$ & $0,388^{* *}$ \\
\hline Остеопротегерин & $0,688^{* *}$ & $0,715^{* *}$ & $0,381^{* *}$ & $0,223^{*}$ \\
\hline
\end{tabular}

в коронарной артерии был связан с ММП-9, уровень которого был выше в кальцинированных бляшках. Также в этих бляшках был выше уровень ММП-1, хотя проведенный далее логистический регрессионный анализ не показал влияния ММП-1 на формирование кальцинированных очагов. Так как большинство кальцинированных бляшек в нашем исследовании было нестабильным, это свидетельствует о том, что возможно ММП-1 играет роль в дестабилизации атеросклеротической бляшки.

Выявлена статистически значимая связь остеопротегерина и остеопонтина со всеми изучаемыми ТИМП (табл. 4), наиболее выраженная с ТИМП-1 и ТИМП-2. Для остеокальцина также выявлена связь со всеми ТИМП, но менее сильная. Выявлена связь уровня остеонектина с ТИМП-3 $(r=0,872 ; p=0,0001)$ и ТИМП-4 ( $r=0.892 ; p=0,0001)$.

Заключение. Полученные результаты свидетельствуют о влиянии изучаемых ТИМП и ММП на развитие атеросклероза и кальцификацию атеросклеротических бляшек в коронарных сосудах, особенно ТИМП-1, ТИМП-2; ММП-1 и ММП-9, и требуют дополнительных исследований.

Исследование проводилось в рамках бюджетной темы государственного задания ААААААА17-117112850280-2, бюджетная поддержка коллекций биоресурсов в рамках Государственного задания 0324-2017-0048 и при финансовой поддержке гранта РФФИ 19-015-00055.

DOI $10.52727 / 2078-256 X-2021-17-3-78-79$

\title{
РОЛЬ ПОВРЕЖДЕНИЯ ДНК В ФОРМИРОВАНИИ ЭНДОТЕЛИАЛЬНОЙ ДИСФУНКЦИИ: ИССЛЕДОВАНИЕ IN VITRO
}

\author{
М.Ю. Синицкий, А.В. Цепокина, А.Г. Кутихин, Д.К. Шишкова, А.В. Понасенко
}

ФГБНУ «Научно-исследовательский институт комплексных проблем сердечно-сосудистых заболеваний», Кемерово, Россия

Введение. Атеросклероз - одно из наиболее распространенных заболеваний сердечно-сосудистой системы, начальным звеном патогенеза которой является формирование эндотелиальной дисфункции, ассоциированной с различными факторами риска, среди которых курение, диабет, гиперхолестеринемия, а также наследственная предрасположенность [1]. Существуют данные о том, что в основе эндотелиальной дисфункции помимо классических факторов риска также лежат генотоксический стресс и повреждение ДНК [2].

Понимание молекулярных механизмов формирования дисфункции эндотелиального монослоя в ответ на генотоксический стресс чрезвычайно важно, учитывая возрастающий уровень генотоксической нагрузки на человека, главным образом от антропогенных источников.

Цель исследования - оценка уровня экспрессии генов, задействованных в патогенезе атеросклероза и являющихся маркерами эндотелиальной дисфункции, а именно генов адгезии лейкоцитов (VCAM1, ICAM1, SELE, SELP), эндотелиальной механотрансдукции (KLF4), эндотелиальной дифференцировки (РЕСАМ1, CDH5, CD34, NOS3), эндотелиально-мезенхимального перехода (SNAI1, SNAI2, TWIST1, GATA4, ZEB1, CDH2), скавенджер-рецепторов (LOX1, SCARF1, CD36, LDLR, VLDR), антиоксидантной защиты (PXDN, CAT, SOD1) и транскрипционного фактора НЕY2 в культурах первичных эндотелиальных клеток коронарной (HCAEC) и внутренней грудной (HITAEC) apтерий человека, экспонированных алкилирующим мутагеном митомицином C (MMC).

Материал и методы. Исследование выполнено на коммерческих культурах первичных эндотелиальных клеток коронарной (НСАЕС) и внутренней грудной (HITAEC) артерий человека, в течение 6 часов экспонированных мутаге- 